\title{
A trouble shared is a trouble halved: The role of family identification and identification with humankind in well-being during the COVID- I 9 pandemic
}

Svenja B. Frenzel ${ }^{*}$, Nina M. Junker', Lorenzo Avanzi², Aidos Bolatov ${ }^{3}$, S. Alexander Haslam ${ }^{4}$, Jan A. Häusser ${ }^{5}$, Ronit Kark ${ }^{6,7}$, Ines Meyer ${ }^{8}$, Andreas Mojzisch ${ }^{9}$, Lucas Monzani ${ }^{10}$, Stephen Reicher ${ }^{11}$, Adil Samekin '2, Valerie A. Schury ${ }^{5}$, Niklas K. Steffens ${ }^{4}$, Liliya Sultanova ${ }^{13}$, Dina Van Dijk ${ }^{14}$, Llewellyn E. van Zyl 1, 15,16,17 and Rolf Van Dick'

'Department of Social Psychology, Goethe University Frankfurt, Germany

${ }^{2}$ Department of Psychology and Cognitive Science, University of Trento, Italy

${ }^{3}$ Department of Biochemistry, Astana Medical University, Nur-Sultan, Kazakhstan

${ }^{4}$ School of Psychology, University of Queensland, Brisbane, Australia

${ }^{5}$ Department of Social Psychology, Justus-Liebig-University Giessen, Germany

${ }^{6}$ Department of Psychology, Bar-Ilan University, Ramat Gan, Israel

${ }^{7}$ School of Business, University of Exeter, UK

${ }^{8}$ School of Management Studies, University of Cape Town, South Africa

${ }^{9}$ Department of Psychology, University Hildesheim, Germany

${ }^{10}$ Ivey Business School, University of Western Ontario, London, Canada

IISchool of Psychology and Neuroscience, University of St Andrews, UK

12 Department of Psychology of Religion and Pedagogy, International Islamic Academy of Uzbekistan, Tashkent, Uzbekistan

${ }^{13}$ Department of Psychology, Branch of Moscow State University Named for M.V. Lomonosov in Tashkent, Uzbekistan

${ }^{14}$ Department of Health Systems Management, Ben-Gurion University of the Negev, Beersheba, Israel

${ }^{15}$ Human Performance Management, Eindhoven University of Technology, The Netherlands

${ }^{16}$ Optentia Research Focus Area, North-West University, Vanderbijlpark, South Africa

${ }^{17}$ Department of HRM, University of Twente, Enschede, The Netherlands

This is an open access article under the terms of the Creative Commons Attribution License, which permits use, distribution and reproduction in any medium, provided the original work is properly cited.

*Correspondence should be addressed to Svenja Frenzel, Department of Social Psychology, Goethe University Frankfurt, TheodorW.-Adorno-Platz 6, 60323 Frankfurt, Germany (email: frenzel@psych.uni-frankfurt.de). 
The COVID-I 9 pandemic has triggered health-related anxiety in ways that undermine peoples' mental and physical health. Contextual factors such as living in a high-risk area might further increase the risk of health deterioration. Based on the Social Identity Approach, we argue that social identities can not only be local that are characterized by social interactions, but also be global that are characterized by a symbolic sense of togetherness and that both of these can be a basis for health. In line with these ideas, we tested how identification with one's family and with humankind relates to stress and physical symptoms while experiencing health-related anxiety and being exposed to contextual risk factors. We tested our assumptions in a representative sample $(N=974)$ two-wave survey study with a 4 -week time lag. The results show that anxiety at Time I was positively related to stress and physical symptoms at Time 2 . Feeling exposed to risk factors related to lower physical health, but was unrelated to stress. Family identification and identification with humankind were both negatively associated with subsequent stress and family identification was negatively associated with subsequent physical symptoms. These findings suggest that for social identities to be beneficial for mental health, they can be embodied as well as symbolic.

The World Health Organization declared the COVID-19 outbreak in December 2019 in Wuhan, China, as a worldwide pandemic (Sohrabi et al., 2020). This international health crisis poses a common threat to humankind and has a tremendous impact on society, the economy and the environment (Chakraborty \& Maity, 2020). Up to date (16 May 2021), over 160 million confirmed COVID-19 cases and over 3.3 million confirmed COVID-19related deaths were reported worldwide (World Health Organization, 2021). In Germany, where the present study was conducted, about 3.5 million people have been infected and, so far, over 86,000 deaths have been reported (Robert Koch Institute, 2021). The COVID19 pandemic is a (life) threatening and unpredictable stressor, which greatly impacts individuals' mental and physical health as reports of significant increases in anxiety, stress, and depression have demonstrated (Wang et al., 2020a, 2020b; Wang, Xia, et al., 2020). In addition, as people are affected by the unfolding pandemic, they may experience a critical increase in anxiety for their own lives and the lives of other people. Yet, not all individuals likely suffer to the same degree because of the pandemic as contextual risk factors such as living in a high-risk area (with higher numbers of infections) or having a family member infected with the coronavirus might elicit stronger strain experiences and physical health complaints.

To slow down the spread of COVID-19, the German government - as most other governments worldwide - implemented strict contact restrictions, reducing interpersonal contacts to a bare minimum (Bundesregierung, 2020a). Even though these social restrictions have been effective in preventing the spread of the virus (Qian \& Jiang, 2020), they have also increased social isolation and loneliness, making people more vulnerable to mental and physical health conditions (Jetten, Reicher, Haslam, \& Cruwys, 2020; Killgore, Cloonen, Taylor, \& Dailey, 2020). These observations frame the conflicting nature of the COVID-19 pandemic: On the one hand, in order to help each other in not catching the virus, people need to avoid direct social contact. On the other hand, people draw strength from feeling socially well-integrated and supported - especially in stressful situations. The theory behind this social cure pbenomenon is the Social Identity Approach (SIA) which states that identifying and being part of multiple social groups is health beneficial (Berkman \& Glass, 2000; Haslam et al., 2008; Holt-Lunstad, Smith, \& Layton, 2010; Steffens, Haslam, Schuh, Jetten, \& van Dick, 2017). Yet, group memberships are not only characterized by physical contact, they also entail a psychological component so that people identify with others and experience the health-related benefits from their social 
groups even if they are physically separate from other group members (Khan, Garnett, Hult Khazaie, Liu, \& Gil de Zúniga, 2020).

On this basis, the present two-wave study examines the associations between family identification and identification with humankind with stress and physical ill-health symptoms during the COVID-19 pandemic. We chose family and humankind as social groups, because different forms of social identification characterize them. With social restrictions in place, families are often the only social group with which individuals can regularly interact and receive direct social support. Thus, people who identify with their families may benefit from the feeling of being socially integrated and supported. By contrast, identifying as part of humankind implies a more symbolic feeling of 'being in this pandemic together' with many group members never meeting and interacting with each other (cf., Anderson, 1991; Khan et al., 2020). Thus, both forms of identification allow testing if social identification of a direct or symbolic nature is negatively related to stress and physical ill-health symptoms.

Therefore, we propose that health-related anxiety and COVID-19 risk factors are positively associated with stress and physical symptoms, whereas family identification and identification with humankind are negatively related to these two outcome variables (see Figure 1 for an overview of our proposed model).

\section{Health consequences of the COVID- 19 pandemic}

Since the COVID-19 outbreak, significant decreases in physical health and increases in self-rated mental problems such as depression, distress, and anxiety have been reported in Germany (Bäuerle et al., 2020). In fact, experiencing any symptoms of COVID-19, like a sore throat, headache, bodily pain or cough, was related to more stress, anxiety, and depressive symptoms, even when the affected individuals were not diagnosed with COVID-19 (Rodríguez-Rey, Garrido-Hernansaiz, \& Collado, 2020). In March 2020, when

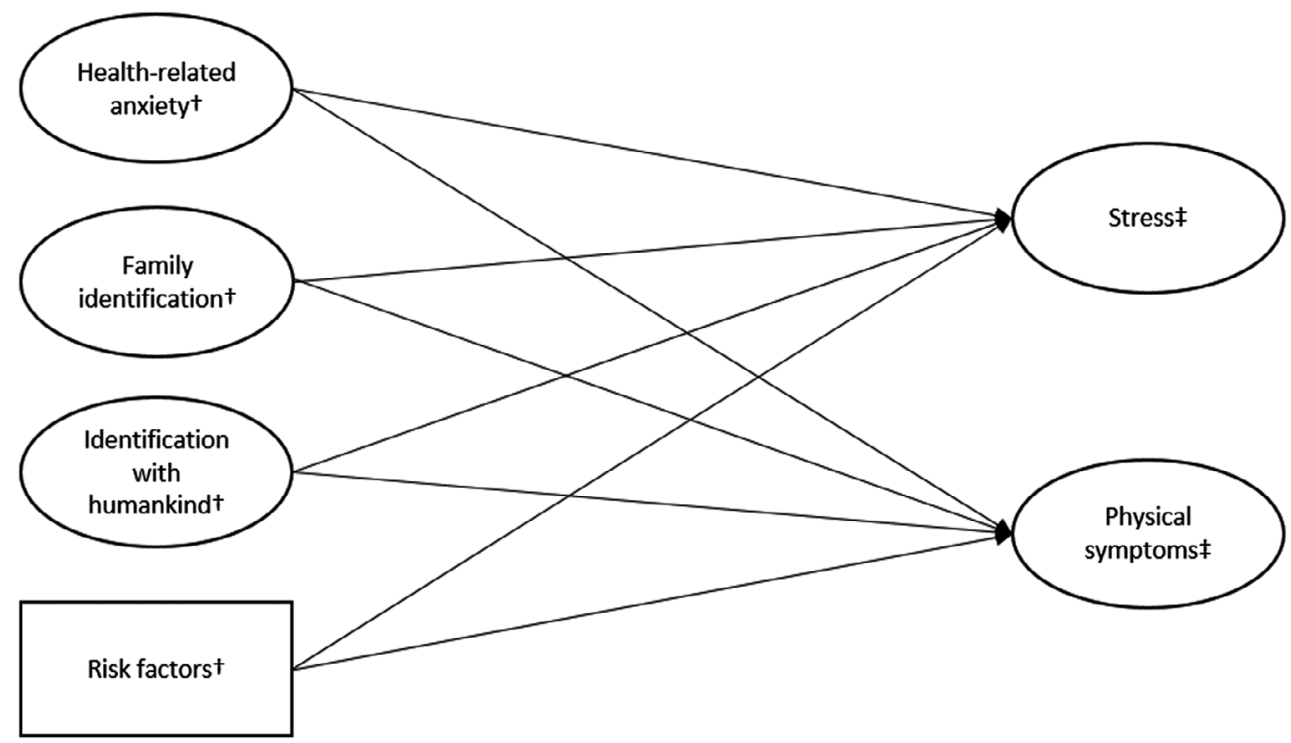

Figure I. Proposed structural model and anticipated relationships between all variables. ${ }^{\dagger}$ measured at Time I. ${ }^{*}$ measured at Time 2. 
the current study was planned, the Robert Koch Institute (22 March 2020) classified the risk for the German population as 'high' and further emphasized that certain factors like age, medical preconditions, or the abode increase the risk of infection and of experiencing severe complications in case of infection. Thus, five COVID-19 'risk factors' were included in this study as they may negatively relate to mental and physical health. These are (1) caring for or (2) living with a person considered being at high risk, (3) having an infected family member or close friend, (4) living in or (5) having recently visited a high-risk area. Although the COVID-19 outbreak has been affecting people nationwide, these risk factors affect some individuals' health and well-being more severely than others. With one or more of these factors applicable to an individual's situation, they may see themselves and closely related others more exposed and vulnerable to the COVID-19 pandemic and experience more mental and physical ill-health. In the following, we will further emphasize these factors and their relations to mental and physical health conditions.

\section{Consequences of the COVID-I 9 risk factors for stress and health}

The first two risk factors imply that people not only have to take care of their own mental and physical health, but also feel responsible for others who are at high risk (e.g., the elderly or people with chronic diseases) and/or whether they live close to such high-risk people. Studies focusing on family caregiving showed health-declining effects of caring responsibilities, whereby highly burdened caregivers reported the poorest health outcomes (Reinhard, Given, Petlick, \& Bemis, 2008).

The third health-threatening risk factor refers to the infection status of a closely related person. If a closely related person is infected with COVID-19, individuals might be both concerned about their loved ones' - and their own health status. Supporting the negative relation between overall health and infection status of a closely related person, results of a meta-analysis on mental health consequences of the COVID-19 pandemic indicate that suspected or confirmed COVID-19 diagnoses of friends or family members were associated with more overall anxiety and depression (Vindegaard \& Benros, 2020). Likewise, in a nationwide survey conducted in Italy, researchers found a positive association between COVID-19 infection of a family member and overall anxiety and a relation between having an infected acquaintance and stress (Mazza et al., 2020). Furthermore, individuals with direct contact with COVID-19-infected individuals reported higher PTSD symptoms than people without close contact (Sun et al., 2021).

Living in or having recently visited a high-risk area represent risk factors four and five. Even though the COVID-19 pandemic 'is more geographically and temporally diffuse than natural and human-made disasters (Raker, Zacher, \& Loew, 2020, pp. 12595), some regions have been more affected by the coronavirus than others (Sohrabi et al., 2020). We expected people who live in these so-called high-risk regions to experience more stress and physical symptoms because they have a higher vulnerability to be infected with the and thus might be more concerned about their health. In line with this assumption, residing in an area with many confirmed COVID-19 cases has been associated with more psychological distress and stronger post-traumatic stress responses in a Chinese sample (Sun et al., 2021; Wang, Xia, et al., 2020). The health-declining effect of a person's environment has also been found in the work context regarding different types of contagious diseases (e.g., SARS, AIDS, or hepatitis): Employees with a higher risk of infection due to their work environment (e.g., health care workers or correctional officers) reported more anxiety and job-related stress (Chong et al., 2004; Hartley, Davila, Marquart, \& Mullings, 2013). Further support for the environmental influence on health 
has been found in a non-disease related context, where people reported more overall stress, anxiety, and more somatic symptoms due to their proximity to the Israeli and Lebanon border, a zone characterized by political uncertainty, war and terror at that time the study was conducted (Kimhi \& Shamai, 2004).

Based on these results, we expect individuals to whom these COVID-19 risk factors apply to experience higher stress perceptions and more physical symptoms. Taken together, we propose that:

$H$ I. Being exposed to more COVID-19 risk factors at Time 1 positively relates to stress at Time 2.

$H$ 2. Being exposed to more COVID-19 risk factors at Time 1 positively relates to physical symptoms at Time 2 .

The consequences of health-related anxiety for stress and health

Besides the objective risk of infection, some people may be more anxious about becoming infected with the virus than others, affecting their stress and health symptoms. In line with this argument, Islam, Bodrud-Doza, Khan, Haque, and Mamun (2020) showed that individuals concerned about family members' health had an elevated stress response during the pandemic. Acute stress responses can be lifesaving by activating the fight-orflight response, yet anxiety over a more extended period impairs the immune and cardiovascular system and increases people's vulnerability to become sick (Suinn, 2001). Thus, if a stressor like health-related anxiety due to the COVID-19 pandemic is active over a longer period, there might be a decline in psychological well-being, particularly increased stress and a deterioration of one's physical health. In line with this reasoning, studies demonstrated that living through a pandemic induces higher levels of health concerns (Li, Wang, Xue, Zhao, \& Zhu, 2020) and general anxiety, as observed during past pandemics such as the swine flu in 2009 and the SARS-1-virus in 2003 (Chong et al., 2004; Wheaton, Abramowitz, Berman, Fabricant, \& Olatunji, 2012). In fact, initial results on the relation between dysfunctional COVID-19-related anxiety, psychological distress, and physical ill-health symptoms show that these are positively associated (Lee, 2020). On this basis, we propose that:

H 3. Health-related anxiety at Time 1 positively relates to stress at Time 2 .

H 4. Health-related anxiety at Time 1 positively relates to physical symptoms at Time 2 .

\section{Social identification and mental and physical health}

Social identification, that is the feeling of being socially integrated and supported, is crucial for mental and physical health (Baumeister \& Leary, 1995; Haslam, Jetten, Cruwys, Dingle, \& Haslam, 2018; Steffens et al., 2017). The theoretical basis of this social identityhealth link is the Social Identity Approach (Haslam, 2004). As social beings, people tend to categorize themselves into different social groups and act according to the respective 
group's norms and values in group-relevant situations. The individual's social identity is the internalization of a group membership as part of the self.

Importantly, groups give us a sense of who we are and enable the individual to cope with stressful situations successfully. For instance, in an experimental setup, Haslam and Reicher (2006) assigned their participants to either the group of 'guards' or 'prisoners'. The prisoners developed a shared social identity within their group, which buffered their stress responses, whereas the lack of a shared social identity within the group of guards lead to higher stress levels, even though they were - objectively - in a superior position. The prisoners' subjective reports of perceiving less stress were further supported by reduced cortisol levels, emphasizing the negative association between social identification and physical health.

Group members who share a social identity provide more mutual social support (Haslam, Jetten, Postmes, \& Haslam, 2009). Furthermore, perceptions of social support relate to greater collective self-efficacy, which in turn relates to less strain (Avanzi, Schuh, Fraccaroli, \& van Dick, 2015; Junker, van Dick, Avanzi, Häusser, \& Mojzisch, 2019). However, to be health beneficial, social support has to be provided by people with whom the individual shares a social identity (Frisch, Häusser, van Dick, \& Mojzisch, 2014).

Conversely, individuals who feel socially isolated and experience a reduction of their social contacts are more vulnerable to become ill (Cohen, Doyle, Turner, Alper, \& Skoner, 2003), report more depression symptoms (Killgore et al., 2020), and have a higher mortality rate (Holt-Lunstad et al., 2010). Indeed, results of a meta-analysis indicate that the effects of loneliness and social isolation on life expectancy are as strong as the effects of other already well-established health-detrimental factors such as smoking (Holt-Lunstadt et al., 2010). Therefore, social identification and the associated factors of social support (collective), self-efficacy, sense-making and providing meaning has also become known as a resource that can act as a 'social cure' (Haslam et al., 2018; Jetten, Haslam, \& Haslam, 2012). In the following, we focus on two particular forms of social identification, namely family identification and identification with humankind and their relation to psychological and physiological health during the COVID-19 pandemic.

\section{Family identification and mental and physical health}

Families can provide social support and easy access to social resources even in difficult situations like the COVID-19 pandemic (Li et al., 2020). For example, family members provide emotional support by calming each other and providing a sense of security. Furthermore, families are an essential source of instrumental support, for instance, in the form of shopping for groceries for someone who does not feel safe leaving the house, sewing facemasks, or providing financial help. Due to the mutual support provided by family members' collective self-efficacy within the family increases, resulting in better overall health outcomes (see for a theoretical analysis: Häusser, Junker, \& van Dick, 2020). Accordingly, and supporting this theoretical approach, family identification predicts better mental and physical health which can be attributed to the 'we'-feeling that arises from sharing a social identity (Bratt, 2015; Sani, Herrera, Wakefield, Boroch, \& Gulyas, 2012; Wakefield, Sani, Herrera, Khan, \& Dugard, 2016). Therefore, we propose that:

H 5. Family identification at Time 1 is negatively associated with stress at Time 2 . 
H 6. Family identification at Time 1 is negatively associated with physical symptoms at Time 2.

Identification with humankind and mental and physical health

Contrary to the family, the broader group 'humanity' is more symbolic and people cannot connect and mutually interact with everybody. Instead, contact is limited to interactions with only a few members of this group. Nevertheless, research shows that direct interactions with other group members do not necessarily enhance the benefits people derive from large-scale group memberships (Khan et al., 2020). In fact, group contact frequency is not related to health and even just thinking about one's social groups and thus making one's own social identity salient has been associated with less depressive symptoms after dealing with stress and failure (Cruwys, South, Greenaway, \& Haslam, 2015; Wakefield et al., 2016).

Even though humankind might be a less salient group than more proximal groups, such as one's family, the COVID-19 pandemic has been affecting individuals across the globe, which likely creates a shared identity and a feeling of 'we are all in this together' (Tajfel, Billig, Bundy, \& Flament, 1971). This assumption is supported by the fact that people behave in favour of humanity and act according to group-relevant norms and values, by staying at home for other people - not particularly for their own health protection, but to protect others (Jetten et al., 2020). One viral example of such collective caring behaviour is the \#IStayHomeChallenge in the UK, where people posted statements of why and for whom they stayed home on their social media profiles (DeSantis, 2020, March 23). Focusing on the health of the collective does not only save lives, but the shared stressful experiences and mutual understanding also reduce stress and physical symptoms (Gallagher, Meaney, \& Muldoon, 2014). Additionally, experiencing a collective trauma strengthens the identification within the affected community and enables a more adaptive reaction of the individual in the aftermath of the trauma (Muldoon, 2020; Muldoon et al., 2017). Therefore, we propose that:

$H$ 7. Identification with humankind at Time 1 is negatively associated with stress at Time 2 .

$H$ 8. Identification with humankind at Time 1 is negatively associated with physical symptoms at Time 2 .

\section{Method}

\section{Participants and procedure}

This study was conducted as part of a multi-national research project on social identification during the pandemic and was approved by the Commerce Faculty Ethics Board (University of Cape Town; REF: REC 2020/03/013). For the present analyses, we used a sample from Germany. Participants in Germany were recruited via Kantar, an online panel provider and received $1.65 €$ for their participation per survey. Before completing the online questionnaire, participants had to agree with the informed consent statement. At the end of the first survey, the respondents were asked if they would like to participate in a follow-up survey four weeks later. A total of 1484 individuals participated 
in the first survey (26 March - 31 March). We excluded nine cases because seven participants participated more than once. We used only responses of their first completions of the survey which resulted in a sample of $N=1475$ at Time 1 . Of these 1475,1015 individuals also completed the second questionnaire four weeks later (27 April -4 May). At Time 2, we identified five people who participated twice and only included their first responses leaving us with a sample of $N=1010$ at Time 2 (attrition rate: $31.53 \%$ ). Data collection started a few days after the German government implemented extensive contact restrictions (Bundesregierung, 2020a). The rapid changes of the pandemic progress and the associated political decisions made it difficult to plan an appropriate retest interval. On the one hand, a longer interval would have enabled us to focus on the longer-lasting health consequences. On the other hand, a longer interval would also have increased the risk of external and uncontrollable factors (e.g., easing of restrictions) influencing our results. In the mid of April 2020 contact, restrictions were extended until 3 May 2020, but the first relaxation of restrictions was announced simultaneously (Bundesregierung, 2020b). Therefore, we used a 4-week time lag to secure comparable circumstances at Time 1 and Time 2 as much as possible.

Buchanan and Scofield (2018) suggested that sufficient checks of data quality should consist of multiple indicators. Therefore, data quality was checked based on response patterns, response time, and answers given to an open answer format question. Participants were flagged when (1) their answer patterns across subsequent subscales did not differ (e.g., a constant response of $3=$ 'neutral'), (2) their response time was less than $50 \%$ of the calculated median of the average response time of the sample (for a similar approach, see Kaluza, Weber, Van Dick, \& Junker, 2021), or (3) their responses to an open answer format question was clearly insincere (e.g., typing random letters). The latter criterion was added because interpretable answers to open-ended questions indicate participant motivation (Schmidt, Gummer, \& Roßmann, 2020). Participants who got flagged two times were excluded from further analysis. Accordingly, at Time 1, 19 participants were excluded due to low data quality and 20 participants were excluded because they did not answer all five 'risk factors'-items. As we planned to calculate a weighted score based on all risk items, a missing value on one of the five items would entail a potential underestimation of the calculated risk. Thus, we decided to exclude cases with missing values. However, we also tested all hypotheses with these participants included into our analyses, which did not change our results. At Time 2, 19 participants were excluded due to questionable data quality. After matching both data sets, the final sample consisted of $N=974$.

In the final sample, the majority of the participants (61.3\%) were employed and $57.1 \%$ reported to have children. Only two participants $(0.2 \%)$ had suffered from and one participant $(0.1 \%)$ indicated to have been cured of COVID-19. 40.3\% of the participants had not been tested $(n=393)$ and $59.2 \%$ were tested negatively $(n=577){ }^{1}$

We compared the age (mean age 51.14 years, $S D=13.76$ ) and gender distributions (52.7\% women) of the final sample $(N=974)$ with the respective distributions of the German population obtained from the Federal Statistical Office (2020, June; 2020). The age distributions show strong resemblances; however, our sample comprised older people (especially in the age range from 40 to 59 years). Therefore, we decided to run all analyses with and without age included as a covariable to compare the results. The sample's gender distribution shows a small surplus of women, which matches the German

\footnotetext{
' One participant did not answer this question.
} 
Table I. Sample distribution across the German federal states based on N $=970$

\begin{tabular}{|c|c|c|c|c|}
\hline \multirow[b]{2}{*}{ Federal states } & \multicolumn{2}{|c|}{ Study Sample } & \multicolumn{2}{|c|}{$\begin{array}{l}\text { Population in state of total } \\
\text { population in Germany }\end{array}$} \\
\hline & $N$ & $\%$ & $N$ & $\%$ \\
\hline Baden-Württemberg & 117 & 12.1 & 11070000 & 13.3 \\
\hline Bavaria & 150 & 15.5 & 13077000 & 15.8 \\
\hline Berlin & 42 & 4.3 & 3645000 & 4.4 \\
\hline Brandenburg & 30 & 3.1 & 2512000 & 3.0 \\
\hline Bremen & 9 & 0.9 & 683000 & 0.8 \\
\hline Hamburg & 28 & 2.9 & $184 \mid 000$ & 2.2 \\
\hline Hesse & 73 & 7.5 & 6266000 & 7.5 \\
\hline Mecklenburg Western Pomerania & 19 & 2.0 & 1610000 & 1.9 \\
\hline Lower Saxony & 90 & 9.3 & 7982000 & 9.6 \\
\hline North Rhine-Westphalia & 191 & 19.7 & 17933000 & 21.6 \\
\hline Rhineland Palatinate & 54 & 5.6 & 4085000 & 4.9 \\
\hline Saarland & II & I.I & 991000 & 1.2 \\
\hline Saxony & 66 & 6.8 & 4078000 & 4.9 \\
\hline Saxony-Anhalt & 27 & 2.8 & 2208000 & 2.7 \\
\hline Schleswig Holstein & 38 & 3.9 & 2897000 & 3.5 \\
\hline Thuringia & 25 & 2.6 & 2143000 & 2.6 \\
\hline Total & 970 & 100.0 & 83021000 & 100.0 \\
\hline
\end{tabular}

Four participants did not indicate their ZIP code.

${ }^{\dagger}$ Federal Agency for Civic Education/bpb (2018, December 3I).

population's distribution (Federal Statistical Office, 2021, May). Additionally, participants were further asked to indicate their ZIP codes to compare the sample's distribution across the federal states in Germany with that of the German population (see Table 1). Additionally, this allowed us to track COVID-19 case numbers according to the participants' current federal state of residence (see Table 2; most cases were recorded in Bavaria, Hamburg and Baden-Wuerttemberg). Overall, the descriptive analysis indicates that the final sample is representative for the German population regarding age, gender, and federal state of living.

\section{Measures}

Besides providing demographic information, participants completed the following items and scales ${ }^{2}$. Unless stated otherwise, all items were answered on a five-point Likert scale from 1 = strongly disagree to 5 = strongly agree, and a scale mean was created for each measure. The complete scales are provided in the Appendix.

\footnotetext{
${ }^{2}$ As this study was part of a larger research project, further measures were included in the study. Only measures relevant to this paper are reported in this manuscript in more detail. Besides the measures reported here, we assessed identification with several social groups (e.g. family, country, humankind), health-related anxiety, threat perceptions, adherence to health recommendations, attitudes towards physical distance and panic buying, and COVID-I 9 risk factors at Time I. In addition to the constructs measured at Time I, we included scales for measuring stress and physical symptoms at Time 2.
} 
Table 2. Categorization of participants' living areas (amount and percentages of COVID-19 cases per 100.000 population)

\begin{tabular}{ll} 
Cases per 100.000 population & $n(\%)$ \\
\hline $0-\leq 5$ & $0(0)$ \\
$>5-\leq 25$ & $19(2.0)$ \\
$>25-\leq 50$ & $195(20.1)$ \\
$>50-\leq 100$ & $461(47.53)$ \\
$>100-\leq 150$ & $295(30.41)^{\dagger}$ \\
$>150-\leq 200$ & $0(0)$ \\
$>200-\leq 250$ & $0(0)$ \\
$>250-\leq 300$ & $0(0)$ \\
$>300$ & $0(0)$ \\
Total & $970(100)$
\end{tabular}

Four participants did not indicate their ZIP code.

During the first survey period (March $26-31$ ), the case numbers (per 100.000 population) were the highest in Hamburg, Baden-Wuerttemberg, and Bavaria (Robert Koch Institute, 2020, March 31).

$\dagger_{\text {Bavaria }}(n=150)$, Hamburg $(n=28)$, and Baden-Wuerttemberg $(n=117)$.

Health-related anxiety (Time I)

Health-related anxiety was measured with five items, each referring to a different social group (sample item: 'At the moment, because of the coronavirus pandemic, I am feeling anxious about my family/ close friends getting seriously ill.'). These items were based on the marker item for state anxiety ('I feel anxious') in the State-Trait Anxiety Questionnaire (Spielberger, Gorsuch, Lushene, Vagg, \& Jacobs, 1983) and adapted to refer to the COVID19 pandemic. Cronbach alpha was .85 .

\section{COVID-I 9 risk factors (Time I)}

Building on the five risk factors described before, we asked participants to answer the following questions with $O=$ no or $1=y e s$ : 'Are you taking responsibility for people who are exposed to high risk (e.g., taking care of parents/grandparents)?', 'Are people who are exposed to high-risk (elderly, chronically ill) living in your household or close by?', 'Has a family member or close relative/ friend been diagnosed with the coronavirus?', 'Do you live in a high-risk area (with many documented cases of the coronavirus)?', and 'Have you recently visited a high-risk area?'.

The degree to which these five risk factors contributed to an additional burden was rated by eleven health and social psychologist who all resided in Germany at the time of data collection. They were asked to compare the five items regarding their burdening degree with each other. Based on their individual perspectives, they assigned a respective percentage value to all five items and ensured that the sum is 100 . Hence, when all factors applied to an individual, the burdening degree due to the risk factors would be $100 \%$. Based on these ratings, a mean weight was assigned to the respective statement and an overall 'risk score' was calculated (mean weights can be found in the Appendix). For example, the raters assigned a mean weight of $M=9.55$ (i.e., roughly 10\%) out of 100 $(100 \%)$ to the aspect 'recently visited a high-risk area'. In order to calculate a risk score ranging from $0-1$, the mean weights were divided by 100 and included into the equation. Higher values indicate a higher burden due to the COVID-19 pandemic. The intraclass 
correlation coefficient (ICC) was .91 $(p<.001)$, indicating a high inter-rater reliability (Cicchetti, 1994; Koo \& Li, 2016). Because only two participants were infected with COVID-19, this item was not included in the final risk score calculation.

\section{Family identification (Time I)}

Four items for measuring individual identification (Doosje, Ellemers, \& Spears, 1995) were adapted to operationalize family identification (sample item: 'I identify with my family'.). Cronbach alpha was .97.

Identification with humankind (Time I)

In order to measure identification with humankind, the same four items by Doosje et al., (1995) were adapted (sample item: 'I identify with other human beings'). Cronbach alpha was .90.

\section{Stress (Time 2)}

Stress was assessed with the short form of the Perceived Stress Questionnaire (Fliege, Rose, Arck, Levenstein, \& Klapp, 2001). Participants were asked to indicate how often the following statements applied to them in the last four weeks on a scale from $1=$ almost never to $4=$ usual. The subscales 'Worries' (sample item: 'You feel frustrated'), 'Tension' (sample item: 'You feel tensed'), 'Joy' (sample item: 'You feel you are doing things you really like'), and 'Demands' (sample item: 'You have too many things to do') can be calculated. As we were interested in the participants' overall stress experience (for a similar approach, see Biehl, Boecking, Brueggemann, Grosse, \& Mazurek, 2019), we collapsed all items into an overall stress score with a Cronbach alpha of .93.

\section{Physical symptoms (Time 2)}

Physical symptoms were measured with the brief form of the Giessen Subjective Complaints List (GBB-8; Kliem et al., 2017). The participants were asked to indicate how often they experienced eight physical symptoms (sample item: 'Stomach ache') in the last four weeks on a scale from $1=$ never to $6=$ very often. Cronbach alpha was .87 .

\section{Statistical analyses}

A sequential data modelling strategy was adopted using SPSS 25 (IBM, 2017) and Mplus v. 8.3 (Muthén \& Muthén, 2019). First, descriptive statistics (means, standard deviations, skewness, kurtosis) and Pearson correlation coefficients were calculated. Data were considered normally distributed if the skewness and kurtosis thresholds did not exceed a range of -2 and +2 (Field, 2009).

Second, a confirmatory factor analytical approach using structural equation modelling (SEM) was conducted to determine the best-fitting model for the data. Here, five different confirmatory factor analytical (CFA) models were fitted to the data and systematically compared. Model fit was established by considering both model fit statistics as well as measurement quality (Shi \& Maydeu-Olivares, 2019). The maximum likelihood parameter estimation with robust standard errors (MLR) was used both for the measurement and 
structural models, as it provides more robust estimations in case of non-normal data distribution (Muthén \& Muthén, 1998-2017).

Third, in order to test our hypotheses, a structural model was estimated based on the best-fitting measurement model. Here, the directional relationships between latent factors were estimated through a path model. We simultaneously tested all hypotheses by regressing stress and physical symptoms (Time 2) on anxiety, COVID-19 risk, family identification, and identification with humankind (all measured at Time 1). Stress and physical symptoms were allowed to covary.

\section{Results}

\section{Dropout analyses}

Participants who only participated in the first survey were significantly younger $(M=41.11, S D=15.63)$ than those who participated in both surveys $(M=51.14$, $S D=13.76), t(810.64)=-11.80, p<.001$. However, there were no gender differences between second and first time only participants $\left(\chi^{2}(1)=1.37, p=.242\right)^{3}$.

Regarding the independent variables, there were no differences between second and first time only participants in terms of health-related anxiety $(t(1434)=-.563, p=.574)$, family identification $(t(1434)=-1.51, p=.13)$, and identification with humankind $(t$ $(1434)=.85, p=.393)$. However, participants who only participated at Time 1 showed higher COVID-19 risk scores $(M=.24, S D=.24 ; t(775.40)=3.23, p=.001)$ than participants who participated in both surveys $(M=.20, S D=.20)$.

\section{Descriptive statistics and correlations}

The descriptive statistics, correlations, and composite reliabilities are summarized in Table 3. All instruments showed acceptable levels of lower (Cronbach Alpha $>0.70$ ) and upper bound limits (Composite reliability $>0.70$ ). The results showed that all scales and subscales were normally distributed with the exclusion of family identification.

Mean scores showed that participants were strongly identified with their families, which resulted in a left-skewed distribution. Compared to family identification, the identification with humankind was lower. Participants reported average levels of anxiety, while the mean risk score was low. Further, the majority of participants found that at least one of the risk factors to be applicable. At Time 2, low to medium stress and physical illhealth symptoms were reported.

Almost all scales were significantly associated. Based on Cohen (1988), there was a medium positive relation between family identification and identification with humankind. Notably, both identity factors were positively associated with healthrelated anxiety and risk (the respective correlational coefficients ranging from .09 to .19 indicate a small relationship between these predictive factors). Health-related anxiety and risk showed both small positive relations to physical symptoms, whereas only healthrelated anxiety but not risk correlated positively with stress at Time 2 (correlation coefficients indicating a medium-sized effect). Thus, these correlations provide initial support for Hypotheses 2, 3, and 4 as we expect health-related anxiety and COVID-19 risk factors to be positively associated with stress and physical symptoms. Finally, family

\footnotetext{
${ }^{3}$ Based on $\mathrm{n}=46 \mathrm{I}$ at Time I (first time only responders) and $\mathrm{n}=974$ at Time 2 (participated at Time I and Time 2) as one person indicated gender $=$ diverse and was excluded from the analysis.
} 


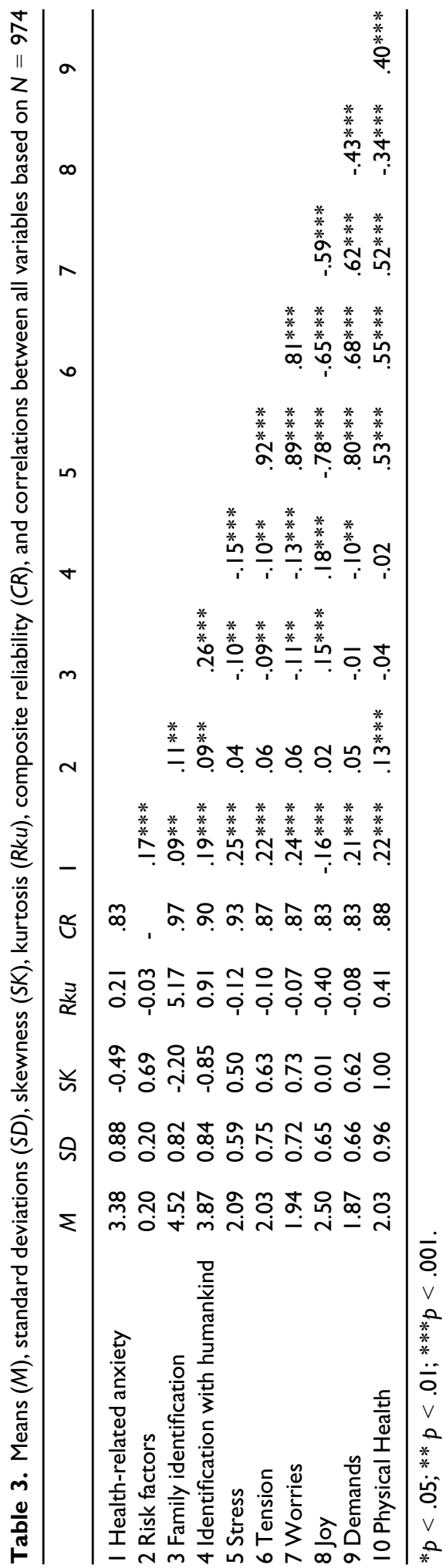


identification and identification with humankind showed small negative correlations with stress at Time 2 but were unrelated to physical symptoms at Time 2, which provides initial support for Hypotheses 5, 6 and 7.

\section{Risk factors}

In Table 4, the frequency and percentages of the participants' responses to the five risk statements at Time 1 are presented. Most participants indicated that they did not take care for any individuals being at high risk (73.7\%). However, at Time 1, 43.1\% lived with or close by a high-risk individual. Only a small minority specified to have a family member or close friend infected with coronavirus (2.7\%). The majority of participants (95.1\%) responded that they had not visited a high-risk area recently. Finally, $10.5 \%$ of the respondents indicated to live in a high-risk area.

\section{CFA of competing measurement models}

Observed measures were treated as indicators for latent factors. One item of the stressscale ('You feel rested') was removed due to a non-significant loading in all models. To enhance model fit for the best-fitting measurement model, we further permitted the residual error terms of item 4 and item 5 of the anxiety scale and item 7 and item 8 from the physical symptom scale to correlate in all models. The risk score was included directly into the five different models (Treiblmaier, Bentler, \& Mair, 2011; Kline, 2015). The following CFA models were tested:

- Model 1: A one-factor model with all items from all instruments loading onto a common first-order factor.

- Model 2: Family identification, identification with humankind, anxiety, physical health, and stress were each specified as single factor latent variables.

- Model 3: Anxiety and physical health were specified as first-order latent factors with items loading onto their a priori factors. The observed variables for measuring family identification and identification with humankind loaded on a first-order latent identity factor. Stress was specified as a hierarchical second-order latent factor, compromising four first-order latent factors (tension, worries, joy, and demands which were measured by four, five, five and five observed variables, respectively). First-order factors on stress were constrained to be equal in order to establish convergence. This model was

Table 4. Risk factors: Numbers (n) and percentages (\%) based on $N=974$

\begin{tabular}{|c|c|c|c|c|}
\hline & \multicolumn{2}{|l|}{ Yes } & \multicolumn{2}{|l|}{ No } \\
\hline & $n$ & $\%$ & $n$ & $\%$ \\
\hline $\begin{array}{l}\text { Are you taking responsibility for people who are exposed to high } \\
\text { risk (e.g., taking care of parents/grandparents)? }\end{array}$ & 256 & 26.3 & 718 & 73.7 \\
\hline $\begin{array}{l}\text { Are people who are exposed to high-risk (elderly, chronically ill) } \\
\text { living in your household or close by? }\end{array}$ & 420 & 43.1 & 554 & 56.9 \\
\hline $\begin{array}{l}\text { Has a family member or close relative/ friend been diagnosed with } \\
\text { coronavirus? }\end{array}$ & 26 & 2.7 & 948 & 97.3 \\
\hline $\begin{array}{l}\text { Do you live in a high-risk area (with many documented cases of } \\
\text { coronavirus)? }\end{array}$ & 102 & 10.5 & 872 & 89.5 \\
\hline Have you recently visited a high-risk area? & 48 & 4.9 & 926 & 95.1 \\
\hline
\end{tabular}


specified to ensure the difference between family identification and identification with humankind.

- Model 4: Family identification, identification with humankind, and physical health were specified as first-order latent factors with items loading onto their a priori factors. The observed variables for measuring anxiety and stress loaded on a first-order latent stress anxiety factor. This model was specified to ensure the difference between healthrelated anxiety and stress.

- Model 5: Family identification, identification with humankind, anxiety, and physical health were specified as first-order latent factors with items loading onto their a priori factors. Stress was specified as a hierarchical second-order latent factor, comprising out of four first-order latent factors (tension, worries, joy, and demands).

The model which fitted the following fit indices best was chosen for further analysis: (1) lowest chi-square-value, (2) root mean square error of approximation (RMSEA: $<0.06$ ), (3) standardized root mean residual (SRMR: $<0.08$ ), (4) Tucker-Lewis Index (TLI: $>0.90$ ), (5) comparative fit index (CFI: $>0.90$ ) and (6) smaller AIC and BIC values (Wang \& Wang, 2012). Measurement quality was a function of significant a priori factor loadings $(\lambda>.40$; $p<.01)$, small residual variances centred around zero, and the absence of multicollinearity between factors (Asparouhov \& Muthén, 2009). The Sattora-Bentler scaled chi-square different test was used to determine the differences between competing measurement models (Satorra \& Bentler, 2010).

\section{CFA results}

The model fit statistics for the five models are summarized in Table 5 and were compared through the Satorra and Bentler (2010) scaled chi-square correction method. The results showed that Model $5\left(\chi^{2}(764, \mathrm{~N}=974)=2404.33 ; p<.001\right.$, scaling correction factor for $M L R=1.15$, CFI $=0.92 ;$ TLI $=0.92 ;$ RMSEA $=0.047$ [CI: 0.045, 0.049]; SRMR $=0.05$ ) fitted the data better than Model 1 (Sartorra-Bentler scaled $\Delta \chi^{2}=5947.39, \Delta d f=14, \Delta$ test scaling correction $=2.82, p<.001$ ) and Model 2 (Sartorra-Bentler scaled $\Delta \chi^{2}=369.70, \Delta d f=4, \Delta$ test scaling correction $=3.07, p<.001$ ), indicating the existence of the four stress subscales tension, worries, joy, and demands and their loading on an overall second-order stress factor. Additionally, according to the fit indices, Model 5 was superior to Model 3 (Sartorra-Bentler scaled $\Delta \chi^{2}=1082.59, \Delta d f=7, \Delta$ test scaling correction $=2.25, p<.001$ ) and Model 4 (Sartorra-Bentler scaled $\Delta \chi^{2}=1238.19, \Delta$ $d f=8, \Delta$ test scaling correction $=2.12, p<.001$ ), supporting the differentiation between family identification and identification with humankind and stress and healthrelated anxiety, respectively. Model 5 also showed acceptable levels of measurement quality with all factor loadings exceeding the suggested thresholds $(\lambda>0.40 ; p<0.01)$, standardized residual variances ranging from .00 to .77 , and no indication of multicollinearity between latent factors. Model 5 was therefore retained for further analyses.

\section{Structural models and hypotheses testing}

The structural path model was estimated based on the best-fitting measurement model (Model 5; see also Figure 2). This model showed good fit $\left(\chi_{(765, N=974)}^{2}=2468.55\right.$, scaling correction factor for $M L R=1.15$, RMSEA $=.05$ [95\% CI: 0.046, 0.050], $\mathrm{CFI}=.92, \mathrm{TLI}=.91, \mathrm{SRMR}=.06) . \mathrm{H}_{1}$ proposed that risk at Time 1 will be positively associated with stress at Time 2 and $\mathrm{H}_{2}$ proposed that risk will be positively associated 


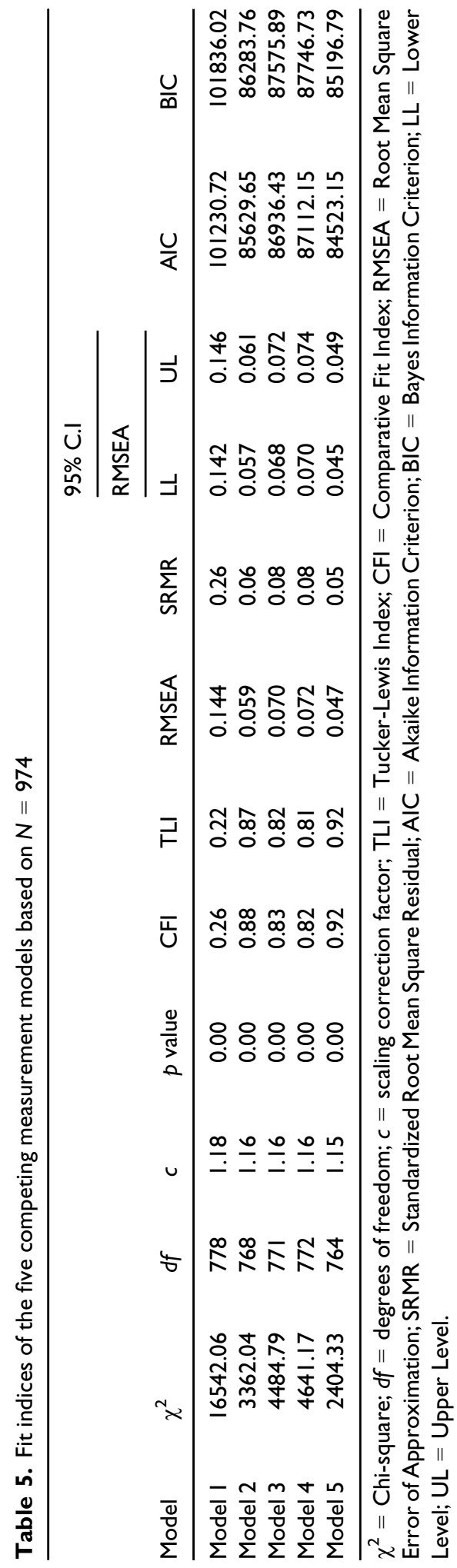




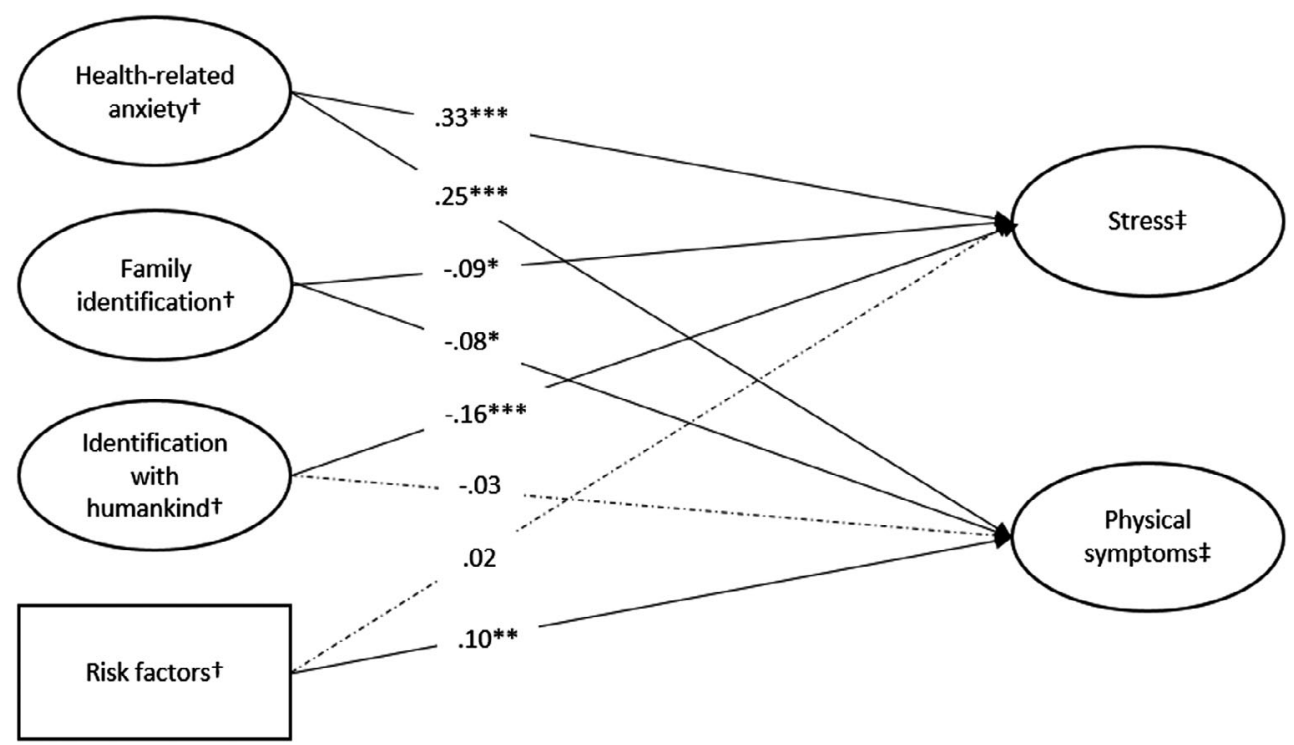

Figure 2. Standardized results of the structural model. Rectangles are observed variables, circles are latent variables; single-headed arrows represent regression paths with standardized regression coefficient; dashed lines indicate non-significant relations between variables. ${ }^{*} p<.05 ;{ }^{*} p<.0 \mathrm{I}$; $* * * p<.001 ;{ }^{\dagger}$ measured at Time I. ${ }^{*}$ measured at Time 2 .

with physical symptoms at Time 2 . Not supporting H1, we did not find a relation between risk and stress $(\gamma=.02, S E=.03, p=.459,95 \% \mathrm{CI}$ : $-0.038,0.083)$. Supporting $\mathrm{H}_{2}$, we found a positive association between risk and physical symptoms $(\gamma=.10, S E=.03$, $p=.004,95 \% \mathrm{CI}: 0.032,0.166) . \mathrm{H}_{3}$ and $\mathrm{H}_{4}$ predicted that health-related anxiety at Time 1 will be positively related to stress and physical symptoms at Time 2 respectively. Supporting $\mathrm{H}_{3}$ and $\mathrm{H}_{4}$, anxiety was positively associated with stress $(\gamma=.33, S E=.03$, $p<.001,95 \%$ CI: $0.264,0.398)$ and physical symptoms $(\gamma=.25, S E=.03, p<.001,95 \%$ CI: $0.184,0.316$ ) at Time $2 . \mathrm{H}_{5}$ proposed a negative relation between family identification at Time 1 and stress at Time 2 and $\mathrm{H}_{6}$ proposed a negative relation between family identification at Time 1 and physical symptoms at Time 2 . Our results support $\mathrm{H}_{5}$ and $\mathrm{H}_{6}$ as family identification was negatively related to stress $(\gamma=-.09, S E=.04, p=.017,95 \%$ CI: $-0.161,-0.016)$ and physical symptoms $(\gamma=-.08, S E=.04, p=.022,95 \%$ CI: $-0.156,-0.012)$. Finally, we predicted that identification with humankind at Time 1 would be negatively related with stress $\left(\mathrm{H}_{7}\right)$ and physical symptoms $\left(\mathrm{H}_{8}\right)$ at that Time 2 . Supporting $\mathrm{H}_{7}$, but not $\mathrm{H}_{8}$, identification with humankind was negatively associated with stress $(\gamma=-.16, S E=.04, p<.001,95 \% \mathrm{CI}:-0.233,-0.078)$ but not with physical symptoms $(\gamma=-.03, S E=.04, p=.448, \mathrm{CI}:-0.101,0.045)$.

As younger people dropped out of the study and did not participate at Time 2, we also run the analysis controlling for participants' age. Model fit was good $\left(\chi^{2}(804, N\right.$ $=974)=2708.23$, scaling correction factor for $M L R=1.15$, RMSEA $=.05$ [95\% CI: 0.047 , $0.051]$, CFI $=.91$, TLI $=.91$, SRMR $=.07$ ). Age was negatively associated with stress $(\gamma=-.25, S E=.03, p<.001,95 \% \mathrm{CI}:-0.313,-0.193)$ and physical symptoms $(\gamma=-.15, S E=.03, p<.001,95 \% \mathrm{CI}:-0.213,-0.080)$. However, including age as a covariable did not change our results. 


\section{Discussion}

The purpose of this study was to investigate how contextual risk factors, health-related anxiety, as well as identification with one's family and with humankind, relate to stress and physical symptoms during the COVID-19 pandemic. We found partial support for our predictions as health-related anxiety was positively associated with stress and physical symptoms, whereas risk factors were only related to physical symptoms. Furthermore, both family identification and identification with humankind were negatively associated with stress. However, only family identification but not identification with humankind was negatively related to physical symptoms.

In line with Hypothesis 2 but contrary to Hypothesis 1, COVID-19 risk factors were only positively related to physical symptoms, but not to stress. One explanation for this missing relation could be that only a minority of participants indicated that they lived in high-risk areas or experienced a person close to them being infected with COVID-19 (when the survey was conducted). Although relatively more participants cared for or lived with a member of a risk group, it could be that they did not necessarily perceive this as a problem or burden. In fact, the German government advised people who were at high risk to restrict their activities even more (compared to the rest of the population) to further decrease their risk of infection. Thus, the desired support provided by 'pandemic caregivers' might only include minor activities, like grocery shopping or more frequent phone calls, which might not necessarily increase stress perceptions. Taken together, the COVID-19 risk factors per se are not stress-inducing as stress responses depend rather on the subjective interpretation of one's own situation (i.e., health-related anxiety). Indeed, our result shows that health-related anxiety was positively related to stress, which is in line with our hypothesis. By embedding these results into the transactional stress model (Lazarus \& Folkman, 1984), health-related anxiety is in line with the primary appraisal process. During this process, people evaluate to what extend the coronavirus poses a threat to themselves and their social groups. This implies that re-evaluating the coronavirus as less dangerous for one's own health and the health of other people could reduce stress responses.

Furthermore, health-related anxiety was also positively associated with physical symptoms, which is in line with previous findings (Suinn, 2001). These results also mirror concerns that the anxiety due to the COVID-19 pandemic can lead to declining physical health - even without an actual COVID-19 infection (Heisz, 2020, March 22). This is because the sole expectation of an aversive event activates neurological fear responses, keeping our body in a constant alert (Phelps et al., 2001). Thus, anticipating an aversive event like a COVID-19 infection over a more extended period can lead to chronic stress exposure which impairs the immune system and, in turn, increases the vulnerability to physical ill-health conditions (Cohen et al., 2012; for a meta-analysis on chronic stress exposure and the effects on the humane immune system see Segerstrom \& Miller, 2004). Our results imply that health-related anxiety transfers to other social groups of an individual, which can elicit mental and physical ill-health symptoms. Conclusively, identifying with different social groups is health beneficial, but it also provides a foundation for feeling anxious and concerned about one's own social groups.

\section{Social cure despite social restrictions}

Family identification was negatively related to stress and physical symptoms. This result is in line with research on the social cure phenomenon, which shows that group 
identification positively affects psychological and physical health (Jetten et al., 2012). This health beneficial effect of family identification may partially be attributed to the availability of social resources and mutual support within the family, but might also be due to increased stress-related self-efficacy or locus of control (Greenaway et al., 2015; Junker et al., 2019; Khan et al., 2014). Importantly, contextual factors (e.g., living alone, being hospitalized, or financial deprivation) might weaken or even invert the curing effect of family identification into a social curse. For instance, family identification might be associated with more - rather than less - strain for hospitalized individuals or those in special care units. As these were not permitted to see their families, they might particularly suffer under the separation (Hart, Turnbull, Oppenheim, \& Courtright, 2020; Luttik et al., 2020). On the contrary, living together as a family during the COVID-19 pandemic is not beneficial per se, as some family members also perceived it as rather burdensome (Evans, Mikocka-Walus, et al., 2020). Additionally, strict lockdown measures and rare opportunities to leave one's home raised concerns about increasing (unreported) cases of domestic violence (Evans, Lindauer, Lindauer, \& Farrell, 2020). Conclusively, future research should take into account living situations and relationships between household members.

While identification with humankind was negatively related to stress, there was no association with physical symptoms. The former result highlights the importance of symbolic group memberships for the individuals' mental health. Similarly, Khan et al., (2020) reported the health beneficial effects of national identification and concluded that 'identification with large-scale groups arguably provides stable anchors in an otherwise rapidly changing world' (p. 209). As the COVID-19 pandemic is an international phenomenon characterized by rapid changes and unknown progression (e.g., steady rise in case numbers, constant adaptions to governmental restrictions), individuals may particularly seek psychological security and stabilization. Feeling a sense of 'we-ness' and knowing that people worldwide are going through the same stressful experience may provide such a secure environment during these turbulent times (Dovidio, Ikizer, Kunst, \& Levy, 2020; Gloster et al., 2020; Van Zyl, 2021; van Zyl, Rothmann, \& ZondervanZwijnenburg, 2021). Through the feeling of being in this pandemic together, people may experience this low-control situation as more controllable. Indeed, the results of an experimental study by Greenaway et al., (2015) support this assumption as they showed that national identification has a positive impact on control perception in a low-control situation which prevented a decrease in well-being. Alike identification with humankind, national identification consists of a psychological component and the impossibility to interact with every group member directly. During times of uncertainty, identification with humankind might serve to maintain the perception of control and is therefore positively related to individual mental health.

The fact that we could not find the proposed association between identification with humankind and physical symptoms might be due to the operationalization of physical health. In the present study, we measured the frequency of objective physical symptoms, whereas in studies that reported relations of identification with large-scale groups and physical health, and assessed the perceived physical health (Khan et al., 2020; Ysseldyk, Haslam, \& Haslam, 2013). Hence, especially the identification with a larger group such as humankind might be related to the negative appraisal of physical health but not the occurrence of physical symptoms per se.

Furthermore, individuals who experience physical symptoms might benefit more from direct support in form of distraction and encouragement which can be provided by proximal (e.g., family) but not by larger and more distant groups (e.g., humanity). 
Concerning this matter, we are aware that we chose two extreme social groups on the physical distance spectrum. Other critical groups worth studying are communities or neighbourhoods, because they represent some kind of middle ground between family and humankind, and furthermore, community identification improves well-being (McNamara et al., 2021). In fact, as a response to the COVID-19 pandemic, community aid groups have been formed worldwide, which enabled mutual support (McDermott, 2020, March 27).

\section{Study limitations}

Despite its strength which includes the large and representative sample and the lagged data collection during a time of a major health crisis, our study is not without limitations. Some study-relevant scales, like health-related anxiety and risk factors, were formulated specifically to fit this study's needs and were therefore not validated beforehand. Additionally, the health-relevant constructs were only measured at Time 2, which does not allow for causal conclusions on the obtained associations to be drawn. Moreover, all study variables were self-reported, eliciting the risk of a common-method bias (Podsakoff, MacKenzie, Lee, \& Podsakoff, 2003). However, the CFA results support the assumption that this was not the case in the present data as the intended model fit the data better than a one-factor model. Nevertheless, future studies should attempt to combine self-report data with objective data. Because of the differences found in the present study compared to previous studies (Khan et al., 2020; Wakefield et al., 2016; Ysseldyk et al., 2013), such a combination may be particularly fruitful for examinations of physical symptoms.

\section{Conclusion}

This study contributes to the existing literature by providing essential insights on the relationship between social identification and mental and physical health during the COVID-19 pandemic. Results reveal that the subjective threat evaluation of oneself and one's own social groups showed a stronger negative association with psychological health than the rather objective COVID-19 risk factors. Beyond this, identifying with one's family and humankind was beneficial for psychological health by being associated with less stress. Nevertheless, there was evidence that only family identification but not identification with humankind was associated with the occurrence of physical symptoms. These findings suggest that (a) identification with family and identification with humankind are independent factors associated with better mental health, (b) identifying with a proximal group (e.g., family) is more helpful for the individual when dealing with concrete physical symptoms, and (c) the importance of identifying with a large collective in the presence of a worldwide stressor should not be underestimated.

Thus, rising awareness that everyone struggles with similar negative experiences due to the COVID-19 pandemic and the need to combat this threat collaboratively, strengthens the perceived identification between people and builds a safer and more secure environment in these challenging times.

\section{Acknowledgements}

This research was supported by a grant from the German Research Foundation awarded to RvD, NMJ, and JAH (DI 848/15-1 and HA 6455/4-1). The data collection for this study was supported by a grant from the association of friends and supporters (Freunde \& Förderer) at Goethe University. 


\section{Conflict of interests}

The authors declare no conflict of interest.

\section{Author contributions}

Svenja Frenzel was involved in writing the original draft and performing formal analysis. Svenja Frenzel, Nina M. Junker, Jan A. Häusser, Andreas Mojzisch, Valerie A. Schury und Rolf van Dick were involved in the conceptualization, methodology, and data curation. Nina M. Junker, Jan A. Häusser und Rolf van Dick were involved in funding acquisition and reviewed and edited the manuscript. Llewellyn van $\mathrm{Zyl}$ was involved in formal analysis. Lorenzo Avanzi, Aidos Bolatov, S. Alexander Haslam, Ronit Kark, Ines Meyer, Lucas Monzani, Stephen Reicher, Adil Samekin, Niklas K. Steffens, Liliya Sultanova, and Dina Van Dijk were involved in reviewing the manuscript and data curation.

\section{Data Availability Statement}

The data that support the findings of this study are available from the corresponding author upon reasonable request.

\section{References}

Anderson, B. (1991). Imagined communities: Reflections on the origin and spread of nationalism (Rev. ed.). London, UK: Verso.

Asparouhov, T., \& Muthén, B. (2009). Exploratory structural equation modeling. Structural Equation Modeling: A Multidisciplinary Journal, 16, 397-438. https://doi.org/10.1080/ 10705510903008204

Avanzi, L., Schuh, S., Fraccaroli, F., \& van Dick, R. (2015). Why does organizational identification relate to reduced employee burnout? The mediating influence of social support and collective efficacy. Work \& Stress, 29, 1-10. https://doi.org/10.1080/02678373.2015.1004225

Bäuerle, A., Steinbach, J., Schweda, A., Beckord, J., Hetkamp, M., Weismüller, B., ... Skoda, E. M. (2020). Mental health burden of the COVID-19 outbreak in Germany: Predictors of mental health impairment. Journal of Primary Care \& Community Health, 11, 1-8. https://doi.org/10.1177/ 2150132720953682

Baumeister, R. F., \& Leary, M. R. (1995). The need to belong: Desire for interpersonal attachments as a fundamental human motivation. Psychological Bulletin, 117(3), 497-529. https://doi.org/10. 1037/0033-2909.117.3.497

Berkman, L. F., \& Glass, T. (2000). Social integration, social networks, social support and health. In L. F. Berkman \& I. Kawachi (Eds.), Social epidemiology (pp. 137-174). Oxford: Oxford University Press.

Biehl, R., Boecking, B., Brueggemann, P., Grosse, R., \& Mazurek, B. (2019). Personality traits, perceived stress, and tinnitus-related distress in patients with chronic tinnitus: Support for a vulnerability-stress model. Frontiers in Psychology, 10, 3093. https://doi.org/10.3389/fpsyg. 2019.03093

Bratt, C. (2015). One of few or one of many: Social identification and psychological well-being among minority youth. British Journal of Social Psychology, 54, 671-694. https://doi.org/10. 1111/bjso. 12105

Buchanan, E. M., \& Scofield, J. E. (2018). Methods to detect low quality data and its implication for psychological research. Behavior Research Methods, 50, 2586-2596. https://doi.org/10.3758/ s13428-018-1035-6 
Bundesregierung (2020a). Besprechung der Bundeskanzlerin mit den Regierungschefinnen und Regierungschefs der Länder am 22.03.2020. Retrieved from https://www.bundesregie rung.de/resource/blob/975226/1733246/e6d6ae0e89a7ffea1 ebf6f32cf472736/2020-03-22mpk-data.pdf

Bundesregierung (2020b). Telefonschaltkonferenz der Bundeskanzlerin mit den Regierungschefinnen und Regierungschefs der Länder am 15. Retrieved from https:// www.bundesregierung.de/breg-de/themen/coronavirus/bund-laender-beschluss-1744224

Chakraborty, I., \& Maity, P. (2020). COVID-19 outbreak: Migration, effects on society, global environment and prevention. Science of the Total Environment, 728,138882 . https://doi.org/ 10.1016/j.scitotenv.2020.138882

Chong, M. Y., Wang, W. C., Hsieh, W. C., Lee, C. Y., Chiu, N. M., Yeh, W. C., . . Chen, C. L. (2004). Psychological impact of severe acute respiratory syndrome on health workers in a tertiary hospital. The British Journal of Psychiatry, 185, 127-133. https://doi.org/10.1192/bjp.185.2. 127

Cicchetti, D. V. (1994). Guidelines, criteria, and rules of thumb for evaluating normed and standardized assessment instruments in psychology. Psychological Assessment, 6, 284-290. https://doi.org/10.1037/1040-3590.6.4.284

Cohen, J. (1988). Statistical power analysis for the behavioral sciences (2nd ed.). Hillsdale, NJ: Lawrence Erlbaum Associates.

Cohen, S., Doyle, W. J., Turner, R., Alper, C. M., \& Skoner, D. P. (2003). Sociability and susceptibility to the common cold. Psychological Science, 14(5), 389-395. https://doi.org/10.1111/14679280.01452

Cohen, S., Janicki-Deverts, D., Doyle, W. J., Miller, G. E., Frank, E., Rabin, B. S., \& Turner, R. B. (2012). Chronic stress, glucocorticoid receptor resistance, inflammation, and disease risk. Proceedings of the National Academy of Sciences of the United States of America, 109(16), 5995-5999. https://doi.org/10.1073/pnas.1118355109

Cruwys, T., South, E. I., Greenaway, K. H., \& Haslam, S. A. (2015). Social identity reduces depression by fostering positive attributions. Social Psychological and Personality Science, 6(1), 65-74. https://doi.org/10.1177/1948550614543309

DeSantis, M. (2020, March 23). What is the \#IStayHomeFor challenge? Kevin Bacon, David Beckham, Elton John and more celebs getting us through social distancing. Evening Standard. Retrieved from https://www.standard.co.uk/insider/alist/i-stay-at-home-for-challenge-celeb rities-twitter-trend-a $4392271 . \mathrm{html}$

Doosje, B., Ellemers, N., \& Spears, R. (1995). Perceived intragroup variability as a function of group status and identification. Journal of Experimental Social Psychology, 31, 410-436. https://doi. org/10.1006/jesp.1995.1018

Dovidio, J. F., Ikizer, E. G., Kunst, J. R., \& Levy, A. (2020). Common Identity and Humanity. In J. Jetten, S. Reicher, S. A. Haslam \& T. Cruwys (Eds.), Together apart-The psychology of COVID19 (1st edn., pp. 141-146). London, UK: SAGE.

Evans, M. L., Lindauer, M., \& Farrell, M. E. (2020). A pandemic within a pandemic - Intimate partner violence during Covid-19. New England Journal of Medicine, 383(24), 2302-2304. https://doi. org/10.1056/NEJMp2024046

Evans, S., Mikocka-Walus, A., Klas, A., Olive, L., Sciberras, E., Karantzas, G., \& Westrupp, E. M. (2020). From 'It has stopped our lives' to 'Spending more time together has strengthened bonds': The varied experiences of Australian families during COVID-19. Frontiers in Psychology, 11, 588667. https://doi.org/10.3389/fpsyg.2020.588667

Federal Agency for Civic Education (2018). Bevölkerung nach Bundesländern. Bevölkerung in absoluten Zablen und Anteile in Prozent, Stichtag: 31.12.2018. Retrieved from https://www. bpb.de/nachschlagen/zahlen-und-fakten/soziale-situation-in-deutschland/61535/bevoelkerungnach-laendern

Federal Statistical Office (2020, June). Bevölkerung - Zahl der Einwohner in Deutschland nach relevanten Altersgruppen am 31. Dezember 2019. Retrieved from https://de.statista.com/ statistik/daten/studie/1365/umfrage/bevoelkerung-deutschlands-nach-altersgruppen/ 
Federal Statistical Office (2021, May). Bevölkerung und Erwerbstätigkeit. Bevölkerungsfortschreibung auf Grundlage des Zensus 2011. Retrieved from https:// www.destatis.de/DE/Themen/Gesellschaft-Umwelt/Bevoelkerung/Bevoelkerungsstand/ Publikationen/Downloads-Bevoelkerungsstand/bevoelkerungsfortschreibung-2010130197004. pdf?_blob=publicationFile

Field, A. (2009). Discovering Statistics Using SPSS., 3rd edn. London: Sage Publication.

Fliege, H., Rose, M., Arck, P., Levenstein, S., \& Klapp, B. F. (2001). Validation of the "Perceived Stress Questionnaire" (PSQ) in a German cohort. Diagnostica, 47(3), 142-152. https://doi.org/10. 1026//0012-1924.47.3.142

Frisch, J. U., Häusser, J. A., van Dick, R., \& Mojzisch, A. (2014). Making support work: the interplay between social support and social identity. Journal of Experimental Social Psychology, 55(4), 154-161. https://doi.org/10.1016/j.jesp.2014.06.009

Gallagher, S., Meaney, S., \& Muldoon, O. T. (2014). Social identity influences stress appraisals and cardiovascular reactions to acute stress exposure. British Journal of Health Psychology, 19, 566-579. https://doi.org/10.1111/bjhp.12056

Gloster, A. T., Lamnisos, D., Lubenko, J., Presti, G., Squatrito, V., Constantinou, M., .. Karekla, M. (2020). Impact of COVID-19 pandemic on mental health: An international study. PLoS One, 15 (12), e0244809. https://doi.org/10.1371/journal.pone.0244809

Greenaway, K. H., Haslam, S. A., Cruwys, T., Branscombe, N. R., Ysseldyk, R., \& Heldreth, C. (2015). From "we" to "me": Group identification enhances perceived personal control with consequences for health and well-being. Journal of Personality and Social Psychology, 109 (1), 53-74. https://doi.org/10.1037/pspi0000019

Hart, J. L., Turnbull, A. E., Oppenheim, I. M., \& Courtright, K. R. (2020). Family-centered care during the COVID-19 era. Journal of Pain and Symptom Management, 60(2), e93-e97. https://doi. org/10.1016/j.jpainsymman.2020.04.017

Hartley, D. J., Davila, M. A., Marquart, J. W., \& Mullings, J. L. (2013). Fear is a disease: The impact of fear and exposure to infectious disease on correctional officer job stress and satisfaction. American Journal of Criminal Justice, 38, 323-340. https://doi.org/10.1007/s12103-0129175-1

Haslam, C., Holme, A., Haslam, S. A., Iyer, A., Jetten, J., \& Williams, W. H. (2008). Maintaining group memberships: Social identity continuity predicts well-being after stroke. Neuropsychological Rebabilitation, 18(5-6), 671-691. https://doi.org/10.1080/09602010701643449

Haslam, C., Jetten, J., Cruwys, T., Dingle, G. A., \& Haslam, S. A. (2018). The new psychology of health - Unlocking the social cure. London, UK: Routledge.

Haslam, S. A. (2004). Psychology in Organizations: The Social Identity Approach. London, UK: Sage Publications. https://doi.org/10.4135/9781446278819

Haslam, S. A., Jetten, J., Postmes, T., \& Haslam, C. (2009). Social identity, health and well-being. An emerging agenda for applied psychology. Applied Psychology: An International Review, 58(1), 1-23. https://doi.org/10.1111/j.1464-0597.2008.00379.x

Haslam, S. A., \& Reicher, S. D. (2006). Stressing the group: Social identity and the unfolding dynamics of responses to stress. Journal of Applied Psychology, 91(5), 1037-1052. https://doi.org/10. 1037/0021-9010.91.5.1037

Häusser, J. A., Junker, N. M., \& van Dick, R. (2020). The how and the when of the social cure: A conceptual model of group-and individual-level mechanisms linking social identity to health and well-being. European Journal of Social Psychology, 50(4), 721-732. https://doi.org/10.1002/ ejsp. 2668

Heisz, J. J. (2020, March 22). Anxiety about the coronavirus can increase the risk of infection - but exercise can help. The Conversation. Retrieved from https://theconversation.com/anxiety-ab out-coronavirus-can-increase-the-risk-of-infection-but-exercise-can-help-133427

Holt-Lunstad, J., Smith, T. B., \& Layton, J. B. (2010). Social relationships and mortality risk: A metaanalytic review. PLoS Med, 7, e1000316(7), e1000316. https://doi.org/10.1371/journal.pmed. 1000316

IBM Corp. (2017). IBM SPSS statistics for windows, Version 25.0. Armonk, NY: IBM Corp. 
Islam, S. D. U., Bodrud-Doza, M., Khan, R. M., Haque, M. A., \& Mamun, M. A. (2020). Exploring COVID-19 stress and its factors in Bangladesh: A perception-based study. Heliyon, 6, e04399(7), e04399. https://doi.org/10.1016/j.heliyon.2020.e04399

Jetten, J., C. Haslam, \& S. A. Haslam (Eds.) (2012). The social Cure: Identity, health and well-being. Hove: Psychology Press.

Jetten, J., Reicher, S. D., Haslam, S. A., \& Cruwys, T. (2020). Together apart-the Psychology of COVID-19. London: SAGE Publications Ltd.

Junker, N. M., van Dick, R., Avanzi, L., Häusser, J. A., \& Mojzisch, A. (2019). Exploring the mechanisms underlying the social identity-ill-health link: longitudinal and experimental evidence. British Journal of Social Psychology, 58, 991-1007. https://doi.org/10.1111/bjso. 12308

Kaluza, A. J., Weber, F., Van Dick, R., \& Junker, N. M.(2021). When and How health-oriented leadership relates to employee well-being - the role of expectations, self-care, and LMX.Journal of Applied Social Psychology, 51(4), 404-424. https://doi.org/10.1111/jasp.12744

Khan, S. S., Garnett, N., Hult Khazaie, D., Liu, J. H., \& Gil de Zúñiga, H. (2020). Opium of the people? National identification predicts well-being over time. British Journal of Psychology, 111, 200214. https://doi.org/10.1111/bjop.12398

Khan, S. S., Hopkins, N., Tewari, S., Srinivasan, N., Reicher, S. D., \& Ozakinci, G. (2014). Efficacy and well-being in rural north India: The role of social identification with a large-scale community identity. European Journal of Social Psychology, 44(7), 787-798. https://doi.org/10.1002/ ejsp.2060

Killgore, W. D., Cloonen, S. A., Taylor, E. C., \& Dailey, N. S. (2020). Loneliness: A signature mental health concern in the era of COVID-19. Psychiatry Research, 290, 113117. https://doi.org/10. 1016/j.psychres.2020.113117

Kimhi, S., \& Shamai, M. (2004). Community resilience and the impact of stress: Adult response to Israel's withdrawal from Lebanon. Journal of Community Psychology, 32, 439-451. https:// doi.org/10.1002/jcop.20012

Kliem, S., Lohmann, A., Klatt, T., Mößle, T., Rehbein, F., Hinz, A., ... Brähler, E. (2017). Brief assessment of subjective health complaints: Development, validation and population norms of a brief form of the Giessen Subjective Complaints List (GBB-8). Journal of Psychosomatic Research, 95, 33-43. https://doi.org/10.1016/j.jpsychores.2017.02.003

Kline, R. B.(2015). Principles and practice of structural equation modeling. 4th edn., New York, NY: Guilford Publications.

Koo, T. K., \& Li, M. Y. (2016). A guideline of selecting and reporting intraclass correlation coefficients for reliability research. Journal of Chiropractic Medicine, 15, 155-163. https://doi. org/10.1016/j.jcm.2016.02.012

Lazarus, R. S., \& Folkman, S. (1984). Stress, appraisal, and coping. New York, NY: Springer.

Lee, S. A. (2020). Coronavirus Anxiety Scale: A brief mental health screener for COVID-19 related anxiety. Death Studies, 44, 393-401. https://doi.org/10.1080/07481187.2020.1748481

Li, S., Wang, Y., Xue, J., Zhao, N., \& Zhu, T. (2020). The impact of COVID-19 epidemic declaration on psychological consequences: a study on active Weibo users. International Journal of Environmental Research and Public Health, 17, 2032. https://doi.org/10.3390/ ijerph17062032

Luttik, M., Mahrer-Imhof, R., Garcia-Vivar, C., Brodsgaard, A., Dieperink, K., Imhof, L., ... Konradsen, H. (2020). The COVID-19 pandemic: A family affair. Journal of Family Nursing, 26 (2), 87-89. https://doi.org/10.1177/1074840720920883

Mazza, C., Ricci, E., Biondi, S., Colasanti, M., Ferracuti, S., Napoli, C., \& Roma, P. (2020). A nationwide survey of psychological distress among Italian people during the COVID-19 pandemic: Immediate psychological responses and associated factors. International Journal of Environmental Research and Public Health, 17, 3165. https://doi.org/10.3390/ ijerph17093165 
McDermott, L. (2020, March 27). How to belp others in Germany during the coronavirus pandemic. The Local. Retrieved from https://www.thelocal.de/20200317/how-to-help-othersin-germany-during-the-coronavirus-pandemic

McNamara, N., Stevenson, C., Costa, S., Bowe, M., Wakefield, J., Kellezi, B., ... Mair, E. (2021). Community identification, social support, and loneliness: The benefits of social identification for personal well-being. The British Journal of Social Psychology, 1-24. https://doi.org/10.1111/ bjso. 12456

Muldoon, O. (2020). Collective trauma. In J. Jetten, S. Reicher, S. A. Haslam \& T. Cruwys (Eds.), Together apart - The Psychology of COVID-19 (pp. 84-88). London: SAGE Publications Ltd.

Muldoon, O. T., Acharya, K., Jay, S., Adhikari, K., Pettigrew, J., \& Lowe, R. D. (2017). Community identity and collective efficacy: A social cure for traumatic stress in post-earthquake Nepal. European Journal of Social Psychology, 47, 904-915. https://doi.org/10.1002/ejsp.2330

Muthén, L. K., \& Muthén, B. O. (1998-2017). Mplus user's guide, Eighth Edition. Los Angeles, CA: Muthén \& Muthén.

Muthén, L. K., \& Muthén, B. O. (2019). Mplus (Version 8.3) [Statistical software]. Los Angeles, CA: Muthén \& Muthén.

Phelps, E. A., O'Connor, K. J., Gatenby, J. C., Gore, J. C., Grillon, C., \& Davis, M. (2001). Activation of the left amygdala to a cognitive representation of fear. Nature Neuroscience, 4(4), 437-441. https://doi.org/10.1038/86110

Podsakoff, P. M., MacKenzie, S. B., Lee, J.-Y., \& Podsakoff, N. P. (2003). Common method biases in behavioral research: A critical review of the literature and recommended remedies. Journal of Applied Psychology, 88(5), 879-903. https://doi.org/10.1037/0021-9010.88.5.879

Qian, M., \& Jiang, J. (2020). COVID-19 and social distancing. Journal of Public Health: From Theory to Practice, 1-3. https://doi.org/10.1007/s10389-020-01321-z

Raker, E. J., Zacher, M., \& Loew, S. R. (2020). Lessons from Hurricane Katrina for predicting the indirect health consequences of the COVID-19 pandemic. Proceedings of the National Academy of Science, 117(23), 12595-12597. https://doi.org/10.1073/pnas.2006706117

Reinhard, S. C., Given, B., Petlick, N. H., \& Bemis, A. (2008). Supporting family caregivers in providing care. In R.G. Hughes (Ed.), Patient safety and quality: An evidence-based handbook for nurses. Rockville, MD: Agency for Healthcare Research and Quality.

Robert Koch Institute (2020, March 31). Coronavirus Disease 2019 (COVID-19). Daily Situation Report of the Robert Koch Institute. Retrieved from https://www.rki.de/DE/Content/InfAZ/N/ Neuartiges_Coronavirus/Situationsberichte/2020-03-31-en.pdf?_blob=publicationFile

Robert Koch Institute (2021). Coronavirus Disease 2019 (COVID-19) Daily Situation Report of the Robert Koch Institute. Retrieved from https://www.rki.de/DE/Content/InfAZ/N/Neuartige s_Coronavirus/Situationsberichte/Mai_2021/2021-05-16-de.pdf?_blob=publicationFile

Rodríguez-Rey, R., Garrido-Hernansaiz, H., \& Collado, S. (2020). Psychological impact and associated factors during the initial stage of the coronavirus (COVID-19) pandemic among the general population in Spain. Frontiers in Psychology, 11, 1540. https://doi.org/10.3389/fpsyg. 2020.01540

Sani, F., Herrera, M., Wakefield, J. R., Boroch, O., \& Gulyas, C. (2012). Comparing social contact and group identification as predictors of mental health. British Journal of Social Psychology, 51(4), 781-790. https://doi.org/10.1111/j.2044-8309.2012.02101.x

Satorra, A., \& Bentler, P. M. (2010). Ensuring positiveness of the scaled difference chi-square test statistic. Psychometrika, 75, 243-248. https://doi.org/10.1007/s11336-009-9135-y

Schmidt, K., Gummer, T., \& Roßmann, J. (2020). Effects of respondent and survey characteristics on the response quality of an open-ended attitude question in web surveys. Methods, Data, Analyses, 14(1), 3-34. https://doi.org/10.12758/mda.2019.05

Segerstrom, S. C., \& Miller, G. E. (2004). Psychological stress and the human immune system: a metaanalytic study of 30 years of inquiry. Psychological Bulletin, 130(4), 601-630. https://doi.org/ 10.1037/0033-2909.130.4.601 
Shi, D., \& Maydeu-Olivares, A. (2019). The effect of estimation methods on SEM fit indices. Educational and Psychological Measurement, 80(3), 421-445. https://doi.org/10.1177/ 0013164419885164

Sohrabi, C., Alsafi, Z., O'Neill, N., Khan, M., Kerwan, A., Al-Jabir, A., . . Agha, R. (2020). World Health Organization declares global emergency: A review of the 2019 novel coronavirus (COVID-19). International Journal of Surgery, 76, 71-76. https://doi.org/10.1016/j.ijsu.2020.02.034

Spielberger, C. D., Gorsuch, R. L., Lushene, R., Vagg, P. R., \& Jacobs, G. A. (1983). Manual for the state-trait anxiety inventory. Palo Alto, CA: Consulting Psychologists Press.

Steffens, N. K., Haslam, S. A., Schuh, S. C., Jetten, J., \& van Dick, R. (2017). A meta-analytic review of social identification and health in organizational contexts. Personality and Social Psychology Review, 21(4), 303-335. https://doi.org/10.1177/1088868316656701

Suinn, R. M. (2001). The terrible twos - anger and anxiety: Hazardous to your health. American Psychologist, 56(1), 27-36. https://doi.org/10.1037/0003-066X.56.1.27

Sun, L., Sun, Z., Wu, L., Zhu, Z., Zhang, F., Shang, Z., . . Liu, W. (2021). Prevalence and risk factors for acute posttraumatic stress disorder during the COVID-19 outbreak. Journal of Affective Disorders, 283, 123-129. https://doi.org/10.1016/j.jad.2021.01.050

Tajfel, H., Billig, M. G., Bundy, R. P., \& Flament, C. (1971). Social categorization and intergroup behavior. European Journal of Social Psychology, 1(2), 149-178. https://doi.org/10.1002/ejsp. 2420010202

Treiblmaier, H., Bentler, P. M., \& Mair, P. (2011). Formative constructs implemented via common factors. Structural Equation Modeling, 18(1), 1-17. https://doi.org/10.1080/10705511.2011. 532693

Van Zyl, L. E. (2021). Social study resources and social wellbeing before and during the intelligent COVID-19 lockdown in The Netherlands. Social Indicator Research, 1-23. https://doi.org/10. 1007/s11205-021-02654-2

Van Zyl, L. E., Rothmann, S., \& Zondervan-Zwijnenburg, M. A. J. (2021). Longitudinal trajectories of study characteristics and mental health before and during the COVID-19 lockdown. Frontiers in Psychology, 12, 1-13. https://doi.org/10.3389/fpsyg.2021.633533

Vindegaard, N., \& Benros, M. E. (2020). COVID-19 pandemic and mental health consequences: systematic review of the current evidence. Brain, Behavior, and Immunity, 89, 531-542. https://doi.org/10.1016/j.bbi.2020.05.048

Wakefield, J. R., Sani, F., Herrera, M., Khan, S. S., \& Dugard, P. (2016). Greater family identificationbut not greater contact with family members-leads to better health: Evidence from a Spanish longitudinal study. European Journal of Social Psychology, 46(4), 506-513. https://doi.org/10. 1002/ejsp.2171

Wang, C., Pan, R., Wan, X., Tan, Y., Xu, L., Ho, C. S., \& Ho, R. C. (2020a). Immediate psychological responses and associated factors during the initial stage of the 2019 coronavirus disease (COVID19) epidemic among the general population in China. International Journal of Environmental Research and Public Health, 17(5), 1729. https://doi.org/10.3390/ijerph17051729

Wang, C., Pan, R., Wan, X., Tan, Y., Xu, L., McIntyre, R., ... Ho, C. (2020b). A longitudinal study on the mental health of general population during the COVID-19 epidemic in China. Brain, Behavior, and Immunity, 87, 40-48. https://doi.org/10.1016/j.bbi.2020.04.028

Wang, H., Xia, Q., Xiong, Z., Li, Z., Xiang, W., Yuan, Y., . . Li, Z. (2020). The psychological distress and coping styles in the early stages of the 2019 coronavirus disease (COVID-19) epidemic in the general mainland Chinese population: A web-based survey. PLoS One, 15(5), e0233410. https:// doi.org/10.1371/journal.pone.0233410

Wang, J., \& Wang, X. (2012). Structural equation modeling: Applications using Mplus. New York, NY: Wiley.

Wheaton, M. G., Abramowitz, J. S., Berman, N. C., Fabricant, L. E., \& Olatunji, B. O. (2012). Psychological predictors of anxiety in response to the H1N1 (swine flu) pandemic. Cognitive Therapy and Research, 36, 210-218. https://doi.org/10.1007/s10608-011-9353-3

World Health Organization (2021). WHO Coronavirus Disease (COVID-19) Dashboard. Retrieved from https://covid19.who.int/ 
Ysseldyk, R., Haslam, S. A., \& Haslam, C. (2013). Abide with me: religious group identification among older adults promotes health and well-being by maintaining multiple group memberships. Aging E Mental Health, 17, 869-879. https://doi.org/10.1080/13607863.2013.799120

Received 23 December 2020; revised version received 17 May 2021

\section{Appendix}

\section{Anxiety}

- At the moment because of the coronavirus situation, I am feeling anxious about getting seriously ill myself.

- At the moment because of the coronavirus situation, I am feeling anxious about my family/ close friends getting seriously ill.

- At the moment because of the coronavirus situation, I am feeling anxious about my neighbours getting seriously ill

- At the moment because of the coronavirus situation, I am feeling anxious about people in my country getting seriously ill.

- At the moment because of the coronavirus situation, I am feeling anxious about all humans getting seriously ill.

\section{Risk factors}

- Are you taking responsibility for people who are exposed to high risk (e.g., taking care of parents/grandparents)? ( $M W=20.90 ; 20 \%)$

- Are people who are exposed to high-risk (elderly, chronically ill) living in your household or close by? ( $M W=27.72 ; 28 \%)$

- Has a family member or close relative/ friend been diagnosed with coronavirus? $(M W=27.72 ; 28 \%)$

- Do you live in a high-risk area (with many documented cases of coronavirus)? $(M W=14.09 ; 14 \%)$

- Have you recently visited a high-risk area? $(M W=9.55 ; 10 \%)$

\section{Family identification}

- I identify with my family.

- I am a part of my family.

- I feel strong ties with my family.

- I am glad to be a part of my family.

\section{Identification with Humankind}

- I identify with other human beings.

- I am a part of humankind.

- I feel strong ties with humankind.

- I am glad to be part of humankind 
82 Svenja Frenzel et al.

\section{Stress}

- You feel rested.

- You feel that too many demands are being made on you.

- You have too many things to do.

- You feel you're doing things you really like.

- You fear you may not manage to attain your goals.

- You feel calm.

- You feel frustrated.

- You are full of energy.

- You feel tense.

- Your problems seem to be piling up.

- You feel you're in a hurry.

- You feel safe and protected.

- You have many worries.

- You enjoy yourself.

- You are afraid for the future.

- You are light-hearted.

- You feel mentally exhausted.

- You have trouble relaxing.

- You have enough time for yourself.

- You feel under pressure from deadlines.

\section{Physical symptoms}

- Stomach ache

- Being easily exhausted

- Palpitations or heart pounding

- Dizziness

- Tiredness

- Feeling bloated or distended

- Neck or shoulder pain

- Backache 